 \\ Journal of Transportation and Logistics \\ 4 (2), 2019
}

Received : November 27, 2019 Accepted : December 29, 2019

http://dx.doi.org/10.26650/JTL.2019.04.02.02

Research Article

\section{Contributions of "Green-Ecoport Approach" to Merchant Trade and Logistics: Comparison of Practices in Turkey and the European Union (EU)}

Fatih Yılmaz | Ministry of Transport and Infrastructure, Ankara, Turkey, yilmazf58@gmail.com

\section{ABSTRACT}

Keywords:

Logistics,

Maritime

Transportation,

Merchant

Trade, Green

Ports, Eco

Ports

About $85 \%$ of the world commodity trade is carried out by sea and merchant ships and maritime trade ports are the most important elements of the international logistics, supply and transportation chain. However, maritime transportation activities have also various environmental impacts from ports and ships for air, water, soil/sediments and ecosystem. In recent years, greenport/ecoport approach, which are becoming widespread in Turkey, especially in European ports, are aimed at disseminating environmentally friendly technologies, minimizing the environmental impacts of ship and port operations, energy saving and consequently more sustainable transportation. In this study, it is aimed to examine the contributions of "green-eco port approach" to logistics activities and merchant trade. In accordance with this aim, green-eco port approach and its international and national practices, specially regarding EU legislation, have been examined, and developable aspects of the implementation for Turkish ports by a comparison of the situation in the EU and in Turkey has have been determined, and an evaluation on contributions of existing greeneco port implementations to logistics activities and merchant trade has been carried out, and some recommendations have been expressed in consequence.
\end{abstract}

\section{“Yeşil-Eko Liman Yaklaşımı"nın Deniz Ticareti ve Lojistik Sektörüne Katkıları: Türkiye ve AB'deki Uygulamaların Karşılaştırması}

\section{öz}

Anahtar Sözcükler :

Dünya mal ticaretinin yaklaşık \%85'i denizyoluyla yapılmakta olup ticaret gemileri ve deniz ticaret limanları, uluslararası lojistik, tedarik ve taşımacılık zincirinin en önemli unsurlarını teşkil etmektedir. Bununla birlikte, deniz taşımacılığı faaliyetlerinin hava, su, toprak/sedimetler ve ekosisteme yönelik limanlar ve gemilerden kaynaklanan çeşitli çevresel etkileri de mevcuttur. Son yıllarda, Avrupa limanları başta olmak üzere, Türkiye'de de yaygınlaşmaya başlayan yeşileko liman yaklaşımı ile çevre dostu teknolojilerin yaygınlaştırılması, gemi ve liman operasyonlarının çevresel etkilerinin minimize edilmesi, enerji tasarrufu ve sonucunda daha sürdürülebilir bir taşımacılık hedeflenmektedir. Bu çalışmada; yeşil-eko liman yaklaşımının deniz taşımacılığı ve lojistik sektörüne katkılarının incelenmesi ve Türkiye ile Avrupa Birliği (AB)'ndeki uygulamaların karşılaştıııması amaçlanmıştır. Bu amaçla; yeşil-eko liman yaklaşımı ile ilgili olarak başta $A B$ düzenlemeleri olmak üzere uluslararası ve ulusal uygulamalar incelenmiş olup Türkiye ve AB'deki uygulamalarının durumuna ilişkin bir karşılaştırma yapılarak Türk limanlarına yönelik uygulamanın geliştirilebilir yönleri belirlenmiş, mevcut yeşil-eko liman uygulamalarının lojistik faaliyetleri ile deniz taşımacılığına yönelik katkıları değerlendirilmiş ve sonuçta bazı öneriler sunulmuştur.

Cite this article as

Yılmaz, F. (2019). "Yeşil-Eko Liman Yaklaşımı"nın Deniz Ticareti ve Lojistik Sektörüne Katkıları: Türkiye ve AB'deki Uygulamaların Karşılaştırması. Journal of Transportation and Logistics, 4(2), 65-78. doi: 10.26650/JTL.2019.04.02.02 


\section{Giriş: Liman Lojistiği ve Deniz Taşımaclığının Çevresel Etkileri}

Tedarik Zinciri Yönetimi Profesyonelleri Konseyi (Council of Supply Chain Management Professionals-CSCMP)'ne (2013) göre; lojistik “müşteri taleplerini karşılamak amacıyla, hizmetler ve ilgili bilgiler de dahil olmak üzere, malların üretim noktasından tüketim noktasına kadar etkin ve verimli bir şekilde taşınması ve depolanmasına yönelik planlama, uygulama ve kontrol prosedürlerinin bir süreci" olarak tanımlanmaktadır (CSCMP, 2013). Elbirlik (2013)'e göre; nakliye, depolama, envanter yönetimi, elleçleme, sipariş işleme, ambalajlama, satın alma ve enformasyon yönetimi süreçlerinin tamamı lojistik yönetiminin kapsamı içerisindedir (Elbirlik, 2008:3).

Bichou (2013)'ya göre; lojistik, doğru ürün veya hizmeti, doğru miktarda ve durumda, doğru fiyata, doğru yere ve doğru müşteriye ulaştırmayı amaçlamakta ve lojistik yönetminin temelini, genel maliyeti azaltmak ve müşteri memnuniyeti için bir firmanın fonksiyon ve süreçlerinin entegrasyonu ve optimizasyonu oluşturmaktadır. Ayrıca, lojistik süreci, gelen (inbound), şirket içi (in-house) ve giden (outbound) lojistiği kapsamakta olup malların, hizmetlerin, insanların ve bilgilerin menşe noktasından tüketim noktasına (ileri lojistik- forward logistics) ve tersine (tersine lojistik- reverse logistics) akışını sağlamakta ve lojistik ve tedarik zinciri yönetimi (SCM) ile ilgili kavramların pek çoğu limanlar için de geçerlidir (Bichou, 2013: 22).

Ascencio ve ark. (2014)'na göre; liman lojistiği zinciri (PLC), ithalatçı ve ihracatçılar, liman otoriteler, liman/terminal operatörleri, gümrükler, gümrük acenteleri, taşımacılık şirketleri (kara ve deniz), freight forwarder/brokerler, vs. gibi uluslararası ticaret süreçlerinde yer alan farklı paydaşlar dahil olmak üzere bir deniz limanı ile çalışan bütün küresel lojistik zincirini kapsamaktadır (Ascencio ve ark., 2014: 444).

Zhen ve ark. (2019)'na göre; limanların lojistik faaliyetleri, gemilerin yanısıra, deniz limanları, hinterlandı, iç nehir limanları ve karayolu/demiryolu/su yolu gibi çok modlu ulaştırma ağlarındaki birçok lojistik faaliyetle ilgilidir. Küresel limanlar ve deniz taşımacılığı ağları, küresel ekonomik büyümenin ve tedarik zinciri ağının gelişiminin ana itici gücü olmakla birlikte, aynı zamanda çok sık gerçekleşen taşımacılık faaliyetleri ve bunun sonucunda ortaya çıkan çok sayıda kirletici madde ve sera gazı emisyonu nedeniyle enerji tüketiminin ve kirliliğin de ana kaynaklarıdırlar. Deniz taşımacılığı faaliyetleri, motorlu araçlar ve endüstriyel işletmelerden sonra üçüncü büyük hava kirliliği kaynağı olarak kabul edilmektedir. Özellikle gemilerden kaynaklanan SOx, NOx ve CO2 emisyonları, insan faaliyetlerinden kaynaklanan dünyadaki yıllık emisyonun sırasıyla \%13, \%15 ve \%2,6'sını teşkil etmeleri bakımından önem arz etmektedirler (Zhen ve ark., 2019:151,152).

Tablo 1'de; Merk (2014)'ün çalışması kapsamında incelenen limanlar arasında deniz taşımacılığı kaynaklı CO2 ve SOx emisyonu oluşumu en fazla olan ilk 10 liman yer almaktadır (Merk, 2014:20). 
Tablo 1. Deniz Taşımacılığı Kaynaklı Emisyon Oluşumu En Fazla Olan İlk 10 Liman (2011)

\begin{tabular}{|l|l|l|l|}
$\begin{array}{l}\text { ilk } 10 \text { liman } \\
\text { (CO2 emisyonu) }\end{array}$ & $\begin{array}{l}\text { Toplam } \\
\text { içindeki payı }\end{array}$ & $\begin{array}{l}\text { ilk 10 liman } \\
\text { (SOx emisyonu) }\end{array}$ & $\begin{array}{l}\text { Toplam } \\
\text { içindeki payı }\end{array}$ \\
\hline 1. Singapore & $\% 5,9$ & 1. Singapore & $\% 6,5$ \\
\hline 2. Hong Kong & $\% 2,2$ & 2. Hong Kong & $\% 2,3$ \\
\hline 3. Rotterdam & $\% 2,0$ & 3. Port Klang & $\% 2,2$ \\
\hline 4. Port Klang & $\% 1,9$ & 4. Tianjin & $\% 2,1$ \\
\hline 5. Tianjin & $\% 1,8$ & 5. Shanghai & $\% 2,0$ \\
\hline 6. Shanghai & $\% 1,7$ & 6. Fujairah & $\% 2,0$ \\
\hline 7. Fujairah & $\% 1,7$ & 7. Busan & $\% 1,7$ \\
\hline 8. Busan & $\% 1,4$ & 8. Kaohsiung & $\% 1,6$ \\
\hline 9. Kaohsiung & $\% 1,4$ & 9. Ulsan & $\% 1,0$ \\
\hline 10. Antwerp & $\% 1,2$ & 10. Beilun & $\% 0,9$ \\
\hline Toplam ilk 10 & $\% 19,0$ & Toplam ilk 10 & $\% 22,3$ \\
\hline Kaynak: Merk $2014 \cdot 20$ & & & \\
\hline
\end{tabular}

OECD üyesi ülkelerin limanlarında deniz taşımacılığı kaynaklı emisyonları inceleyen Merk (2014) tarafından yapılan araştırmada; Mayıs 2011 itibariyle limanlarda deniz taşımacılığı kaynaklı 18,6 milyon ton CO2 (2050'de 70 milyon tona çıkacağı), 0,4 milyon ton NOx (2050'de 1,3 milyon tona çıkacağı), 0,3 milyon ton SOx, 0,03 milyon ton PM10, 0,03 milyon ton PM2,5, 0,03 milyon ton $\mathrm{CO}$ ve 0,002 milyon ton $\mathrm{CH} 4$ emisyonu oluştuğu; söz konusu emisyonların \%85'inin konteyner ve tanker gemilerinden kaynaklandığı; limanlardaki deniz taşımacılığı kaynaklı emisyonların çoğunun Asya ve Avrupa'da oluştuğu (CO2 emisyonlarının \%58'i); emisyonların OECD limanlarına yıllık maliyetinin toplamda yaklaşık 12 milyar Euro olarak tahmin edildiği belirtilmiştir (Merk, 2014:4-37).

Gemilerden atmosfere salınan söz konusu emisyonlar, potansiyel olarak insan sağlığına zarar verebilmekte, asit yağmurlarına neden olabilmekte ve aynı zamanda küresel ısınmaya katkıda bulunabilmektedirler (Uluslararası Denizcilik Örgütü (IMO, 2019a).

Tablo 2'den de görüleceği üzere, deniz taşımacılığı faaliyetlerinin hava, su, toprak ve ekosisteme yönelik olarak limanlar ve gemilerden kaynaklanan çeşitli çevresel etkileri mevcuttur. 
Tablo 2: Deniz Taşımacılığı Faaliyetlerinden Kaynaklanan Çevresel Etkiler

\begin{tabular}{|c|c|c|c|c|c|c|c|c|c|c|c|c|c|c|c|}
\hline \multicolumn{2}{|c|}{ Faaliyetler/Etkiler } & \multicolumn{5}{|c|}{ Hava } & \multicolumn{2}{|c|}{ Su } & \multicolumn{4}{|c|}{$\begin{array}{l}\text { Toprak/sedimentl } \\
\text { er }\end{array}$} & \multicolumn{3}{|c|}{ Ekosistem } \\
\hline \multirow{13}{*}{$\begin{array}{l}\frac{\pi}{0} \\
\frac{\pi}{\pi} \\
\frac{\pi}{5} \\
\frac{D}{ \pm}\end{array}$} & Manevra & $x$ & $\bar{x}$ & $x$ & & $\bar{x}$ & & $x$ & & $x$ & $\bar{x}$ & & & & \\
\hline & $\begin{array}{l}\text { Terminallerde yükleme-boşaltma } \\
\text { operasyonları }\end{array}$ & $x$ & $x$ & $x$ & $x$ & $x$ & $x$ & & $x$ & $x$ & & & & & $x$ \\
\hline & $\begin{array}{l}\text { Binalar (ışıklandırma, ısınme soğutma, } \\
\text { havalandırma vb.) }\end{array}$ & $x$ & $x$ & $x$ & & $x$ & & & & $x$ & & & & & $x$ \\
\hline & Deniz dibi taraması & $x$ & $\mathrm{X}$ & & & $x$ & $x$ & $\mathrm{X}$ & & $\mathrm{X}$ & & & $x$ & $x$ & $x$ \\
\hline & Kara trafiği (ağır vasıta, demiryolu vb.) & $\mathrm{x}$ & $\mathrm{x}$ & $\mathrm{x}$ & & $\mathrm{x}$ & $\mathrm{x}$ & & $\mathrm{x}$ & $\mathrm{x}$ & & & $\mathrm{x}$ & $\mathrm{x}$ & \\
\hline & Atık bertarafı/illegal deşarj & $x$ & $x$ & & $x$ & $x$ & $x$ & $x$ & $x$ & $x$ & & $x$ & $x$ & $x$ & $x$ \\
\hline & $\begin{array}{l}\text { Liman genişlemesi/altyapı inşaatı ve } \\
\text { onarım işleri }\end{array}$ & $x$ & $x$ & $x$ & & $x$ & $x$ & $x$ & $x$ & $x$ & $x$ & $x$ & $x$ & $x$ & $x$ \\
\hline & Yakınt birikintileri & & & & $\mathrm{x}$ & & $x$ & & $x$ & & & $x$ & $x$ & $x$ & $x$ \\
\hline & Balast suyu deşarjı & & & & & & $x$ & $\mathrm{X}$ & $x$ & & & & $x$ & $x$ & $x$ \\
\hline & Pis su deşarjı & & & & $x$ & & $x$ & $x$ & $x$ & & & & $x$ & $x$ & $x$ \\
\hline & $\begin{array}{l}\text { Dökme yük elleçlemesi ve yük } \\
\text { hareketleri }\end{array}$ & $\mathrm{x}$ & & & & $x$ & $x$ & & $\mathrm{x}$ & $x$ & & & & & $x$ \\
\hline & Endüstriyel faaliyetler & $x$ & & & & $x$ & $x$ & & $x$ & $x$ & & $x$ & $x$ & $x$ & $x$ \\
\hline & Döküntüler & & & & & & $x$ & $\mathrm{X}$ & $x$ & & & & $x$ & $x$ & $\mathrm{x}$ \\
\hline \multirow{4}{*}{$\frac{\text { Ũ̉ }}{\mathrm{N}}$} & Seyir & $x$ & $x$ & & & $x$ & & & & $x$ & & & $x$ & $x$ & \\
\hline & illegal deşarj & & & & & & $x$ & $x$ & $x$ & & & & $x$ & $x$ & $x$ \\
\hline & Pis su deşarjı & & & & & & $x$ & $x$ & $x$ & & & & $x$ & $x$ & $x$ \\
\hline & Döküntüler & & & & & & $x$ & $x$ & $x$ & & & & $x$ & $x$ & $x$ \\
\hline \multirow{3}{*}{ 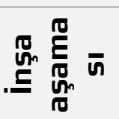 } & Gemi boyama & $x$ & $x$ & & & $x$ & & $x$ & & $x$ & $x$ & & $x$ & $x$ & $x$ \\
\hline & Metal işçiliği & $x$ & $\mathrm{X}$ & & & $x$ & & $x$ & & $X$ & $X$ & & $x$ & $x$ & $x$ \\
\hline & Gemi söküm & $x$ & $x$ & $x$ & & $x$ & & $x$ & & $x$ & $x$ & & $x$ & $x$ & $x$ \\
\hline
\end{tabular}

Kaynak: Jastrzabek ve ark., 2018:3.

Deniz taşımacılığının daha temiz ve daha yeşil olmasını sağlamak için IMO, uluslararası deniz taşımacılığından kaynaklanan sera gazı emisyonlarının ele almak için iki yönlü bir yaklaşım benimsemiştir. İlk olarak, IMO, "1997 Protokolü" ile MARPOL73/78 Sözleşmesinin eklerine 19 Mayıs 2005'ten itibaren yürürlüğe girmek üzere “EK VI: Gemilerden Kaynaklanan Hava Kirliliğinin Önlenmesine ilişkin Kurallar" başıklı yeni bir bölüm ekleyerek uluslararası deniz taşımacılığından kaynaklanan sera gazı emisyonlarını azaltmak için zorunlu enerji verimliliği önlemlerini kabul etmiştir. ikinci olarak ise, IMO, söz konusu düzenlemelerin uygulanmasını desteklemek, inovasyon ve teknoloji transferini teşvik etmek için küresel kapasite geliştirme projeleri yürütmektedir. Nisan 2018'de, IMO Deniz Çevresini Koruma Komitesi (EMPC), gemilerden kaynaklanan sera gazı emisyonlarının azaltılması konusundaki başlangıç stratejisini kabul ederek bir vizyon ortaya koymuştur. Bu vizyon çerçevesinde, teknolojik yenilikler ve alternatif yakıtların ve/veya enerji kaynaklarının teşvik edilmesi, yeni gemiler için Enerji Verimliliği Dizayn İndeksi (EEDI) aşamalarının uygulanmasıyla gemilerin karbon yoğunluğunun azaltılması, taşıma başına CO2 emisyonunun azaltılması, deniz taşımacılı̆ından kaynaklanan CO2 emisyonunun 2008'e kıyasla 2030 yılına kadar \%50 ve 2050 yılına kadar \%70 azaltılması ve bu sayede 2015 yılında Birleşmiş Milletler İklim Değişikliği Çerçeve Sözleşmesi (UNFCCC) ile kabul edilen ve 2016 yılında yürürlüğe giren İklim Değişikliği Hakkında Paris Anlaşmasının “bu yüzyılda küresel sıcaklık artışını 2 oC'nin altına düşürmek ve 1,5 oC ile sınırlandırmak" şeklindeki sıcaklık hedefleri ile tutarlı bir şekilde, deniz taşımacılığından kaynaklanan toplam sera gazı emisyonlarının (GHG) 2008 yılına kıyasla 2050 yılına kadar \%50 azaltılması hedeflenmektedir (IMO, 2019a). Deniz taşımacılığından kaynaklanan hava kirliliğinin azaltılması, IMO'nun yanısıra, Avrupa Birliği (AB)'nin de üzerinde hassasiyetle durduğu bir konudur. 
Chengpeng ve ark. (2018)'na göre; kaçınılmaz olarak küresel çevreyi etkileyen uluslararası deniz taşımacııı̆ında limanların önemli bir rolü bulunmaktadır ve uygun olmayan liman operasyonlarının çevre üzerindeki etkilerini azaltmak için "yeşil liman (green port)" kavramı (konsepti) geliştirilmiştir (Chengpeng ve ark., 2018: 431). Vaio ve Varriale (2018) tarafından yapılan bir literatür incelemesinde; 1997-2017 yılları arasında limanların çevresel etkileri ile ilgili yapılmış olan araştırmalarda, gemi kaynaklı emisyonlar ve hava kirliliği, gemi kaynaklı deniz kirliliği, atıklar, gürültü kirliliği vb. gibi teknik konuların, "çevre yönetimi (environmental management)", "çevresel sürdürülebilirlik (environmental sustainability), "çevresel performans (environmental performance)", "çevre ekonomisi (environmental economics)" vb. gibi konularla beraber incelendiği görülmektedir (Vaio ve Varriale, 2018: 1-35). Dolayısıyla, yeşil liman konsepti, esasen tüm bu konularla ilgilidir.

\subsection{Yeşil Liman (GreenPort) / Eko Liman (EcoPort) Konsepti}

1990'lı yıllarda, Avrupa'nın önde gelen 7 limanının yöneticisi çevre konusunda limanlar arasındaki işbirliğini ve bilgi paylaşımı geliştirmek amacıyla "Ecoports" adında bir inisiyatif (platform) kurmuş, kendine özgü metodlarla limanlardaki çevresel riskleri belirleme, Avrupa ortalaması ile mukayese etme ve uzman tavsiyeleri sağlama konularında diğer Avrupa limanlarını da desteklemeye başlamış ve 2011'den itibaren Avrupa Deniz Limanları Organizasyonu (The European Sea Ports Organisation-ESPO) bünyesine entegre olmuştur (EcoPorts, 2019).

ESPO tarafından 2012 yılında yayımlanan “ESPO Green Guide (Yeşil Rehber)" raporuna (ESPO, 2012) göre; en iyi iş uygulamalarından hareketle bir limanın gelişiminine yönelik vizyonun sürdürülebilirlik ve çevresel konulardaki trenleri de kapsaması gerekmektedir. Ayrıca, limanların gelişiminde sosyal, ekonomik ve çevresel hususlar arasındaki dengenin ve "kendi güncel ihtiyaçlarını gelecek nesillerin imkanlarından ödün vermeden karşılayabilme" şeklindeki "sürdürülebilir gelişme (sustainable development)" yaklaşımın göz önünde bulundurulması ile çevresel yönetim perspektifinin liman otoritesini, liman saha operasyonlarını ve taşımacılık/lojistik zincirini kapsaması gerekmektedir. Sosyal kapsam genellikle doğrudan veya dolaylı istihdama katkı, liman ve şehir arasındaki etkileşim ve ilişki, bilgi geliştirme ve eğitime katkı ile limanı çevreleyen alanın "yaşanabilirliği" gibi unsurlarla ilgilidir. Ekonomik açıdan bakıldığında, yatırımın geri dönüşü, liman alanının etkin kullanımı ve performansını maksimize etmesine yönelik kolaylıklar sağlanması çok önemlidir. Çevresel boyut ise, çevresel performans ve çevre yönetimiyle ilgilidir. Çevresel hususlar, liman alanının konum ve özelliklerine göre her bir liman için farklı olabilir. Son 10 yılda liman çevre yönetimi "nokta odaklı" uygulamadan "entegre liman bölgesi yönetimi" konseptine doğru ilerlemiştir. Limanı kullananlar ve gemi sahipleri, "kirleten öder" prensibi doğrultusunda, en gelişmiş ve sürdürülebilir teknolojilerin kullanılmasından birincil derecede sorumlu taraflardır (ESPO, 2012: 10-15).

Türkiye Liman İşletmecileri Derneği (Türklim)'in web sitesinde de yer alan “Yeşil Liman Raporu/Yeşil Liman Politika, Düzenleme ve Uygulamaları" başlıklı rapora (Türklim, 2013) göre; "yeşil liman politikası"nın, doğal yaşam açısından ekosistemi ve deniz tabiatını korumak ve iyileştirmek, hava kalitesi açısından liman faaliyetlerinin neden olduğu zararlı emisyonları azaltmak, su kalitesi açısından liman ve kıyı suların temizliğini sağlamak, toprak/sedimentler açısından liman bölgesindeki kirli 
toprakların temizlenmesini sağlamak, paydaşların eğitimi açısından liman çevresi paydaşlarının liman operasyonlarının ve çevresel programlara yöneliş işbirliği ve eğitimini gerçekleştirmek, sürdürülebilirlik açısından liman içi yapı tasarım, operasyon ve yönetim uygulamalarını gerçekleştirmek şeklinde altı temel bileşeni olduğu belirtilmektedir (Türklim, 2013).

Mataracı (2016)'ya göre; yeşil liman yaklaşımının temelini “çevresel açıdan performansı yüksek liman işletmeciliği" oluşturmakta ve sürekli gelişmeyi hedefleyen stratejiler, yenilikçi teknolojiler, uygun yatırımlar ile günümüz ve gelecek ihtiyaçlarını karşılayabilen limanlar "sürdürülebilir liman" olarak kabul edilmekte olup limancilık faaliyetinin sürdürülebilirliğini sağlamak için hava kirliliği, gürültü kirliliği, gemi kaynaklı kirlilikler, atık oluşumu, enerji tüketimi, su kalitesi, iş sağlığı ve güvenliği gibi pek çok farklı konunun bir arada ele alınması gerekmekte ve özellikle son yıllarda önemi artan alternatif ve yenilenebilir enerji kaynaklarının limanlarda kullanımı ile enerji ve yakıt verimliliği geliştirilebilmektedir. Limanlarda hava kalitesini arttıran ve gürültü kirliliğini azaltan uygulamaların başında limana yanaşan gemilere sahilden elektrik enerjisi sağlanması (cold-ironing) uygulaması gelmekle birlikte, uluslararası standart eksikliği ve farklı ülkelerin elektrik tedarik sistemlerinde farklı gerilimler ve frekanslar kullanılması bu teknolojinin kullanımında kısıtııık oluşturmaktadır (Mataracı, 2016:5-6, 63).

Limanların çevre yönetiminde gemi kaynaklı çevre kirliliği etmenlerinin önemli bir rolü bulunması, söz konusu etmenlerin daha detaylı ele alınmasını gerektirmektedir.

\section{Gemi Kaynaklı Çevre Kirliliği Etmenleri}

Gemi operasyonları ve deniz kazalarına bağlı sebeplerle deniz çevresinin kirlenmesini önlemeye yönelik kuralları içeren en temel uluslararası sözleşme, IMO tarafından 2 Kasım 1973'te kabul edilen Gemilerden Kaynaklanan Kirliliğin Önlenmesine İlişkin Uluslararası Sözleşme (MARPOL)'dir. Özellikle 1973-1976 yılları arasında meydana gelen tanker kazaları, Sözleşmenin "1978 Protokolü" ile tadil edilmesine yol açmıştır. Sözleşmenin içerdiği ekler, konuları ve yürürlük tarihleri Tablo 3’te gösterilmektedir (IMO, 2019b).

Tablo 3: MARPOL 73/78 Sözleşmesi Ekleri

\begin{tabular}{|l|l|c|}
\hline & \multicolumn{1}{|c|}{ Başlık } & Yürürlük tarihi \\
\hline Ek I & Prevention of Pollution by Oil & 2 Ekim 1983 \\
\hline Ek II & Control of Pollution by Noxious Liquid Substances in Bulk & 2 Ekim 1983 \\
\hline Ek III & Prevention of Pollution by Harmful Substances Carried by Sea in Packaged Form & 1 Temmuz 1992 \\
\hline Ek IV & Prevention of Pollution by Sewage from Ships & 27 Eylül 2003 \\
\hline Ek V & Prevention of Pollution by Garbage from Ships & 31 Aralık 1988 \\
\hline Ek VI & Prevention of Air Pollution from Ships & 19 Mayıs 2005 \\
\hline
\end{tabular}

Kaynak: IMO, 2019b.

Tablo 3'ten de görüldüğü üzere, Ek I petrol kaynaklı kirliliğini, Ek II dökme halde taşınan zehirli sıvı maddelerden kaynaklanan kirliliği, Ek III denizde paketli halde taşınan zararlı maddelerden kaynaklanan kirliliği, Ek IV gemilerden kaynaklanan pis su kirliliğini, EK V gemilerden kaynaklanan çöp kirliliğini, EK VI gemilerden kaynaklanan hava kirliliğini önlemeye yönelik kuralları içermektedir.

Aynı zaman da limanları/terminalleri de yakından ilgilendireren gemi kaynaklı söz konusu çevre kirliliği etmenlerini, gemi kaynaklı hava (atmosfer) kirliliği ve gemi 
kaynaklı deniz çevresi kirliliği etmenleri olarak iki ana başlık altında sınıflandırarak incelemek mümkündür.

\subsection{Gemi Kaynaklı Deniz Kirliliği}

Ek I-Petrol Kirliliğinin Önlenmesi: Deniz kazası ve gemi operasyonlarından kaynaklanan petrol kirliliğinin önlenmesine yönelik kuralları içermekte olup petrol tankerleri için çift cidar zorunluluğu, ham petrol yıkama sistemi, ayrılmış balast tankları, atıl gaz sistemi gibi özel ve ağırlaştırılmış kurallar ve denize petrol içeren atık su veya sintine suyu basılmasının çok sıkı kurallarla düzenlendiği özel deniz alanları tanımlanmıştır (IMO, 2019b).

Ek II-Dökme Halde Taşınan Zehirli Sıvı Maddelerden Kaynaklı Kirliliğinin Önlenmesi: Deniz kazası ve gemi operasyonları sonucu dökme halde taşınan zehirli kimyasal sıvı maddelerin denize karışmasını önlenmeye ve gemiden tahliyesine yönelik kuralları içermekte olup söz konusu maddeler tehlike derecesine göre sınıflandırılarak bu maddelerin her çeşit artıklarının limanlarda/terminallerdeki atık alım tesislerine verilmesi ile en yakın karadan 12 deniz mili içerisinde zehirli madde içeren atıkların denize basılamayacağına ilişkin düzenlemeleri içermektedir (IMO, 2019b).

Ek III-Denizde Paketli Halde Taşınan Zararlı Maddelerden Kaynaklı Kirliliğin Önlenmesi: Ek III'ün ekinde veya International Maritime Dangerous Goods Code (IMDG Code) kapsamında yer alan, denizi kirletici özelliği bulunan ve paketli halde taşınan zararlı maddelerin paketlenmesi, markalanması, etiketlenmesi, dokümantasyonu, istiflenmesi, miktar sınırlandırması, istisnalar ve bildirimlere ilişkin kuralları içermektedir (IMO, 2019b).

Ek IV-Gemi Kaynaklı Pis Su Kirliliğinin Önlenmesi: Gemilerin tuvalet, banyo, revir, canlı hayvan mahalli vb. gibi yerlerindeki pis/foseptik sularının en yakın karadan 12 deniz mili içerisinde denize basılmayacağını, limanlarda/terminallerde gemilerin pis sularını verebilecekleri tesislerin bulunması ile pis su kirliliğinin önlenmesine yönelik özel deniz alanları tanımlanmasına ilişkin düzenlemeleri içermektedir (IMO, 2019b).

Ek V-Gemi Kaynaklı Çöp Kirliliğinin Önlenmesi: Gemide biriken plastik, yemek artıkları, cam, metal, ambalaj artıkları gibi çöplerin sınıflandırılması, özel durumlar hariç çöplerin denize atılmaması, plastik ürünlerinin denize atılmasının tamamen yasaklanması ve genel prensip olarak bütün çöplerin ve yük atıklarının limanlarda/terminallerde atık alım tesislerine verilmesine ilişkin düzenlemeleri içermektedir (IMO, 2019b).

\subsection{Gemi Kaynaklı Hava (Atmosfer) Kirliliği}

Ek VI-Gemi Kaynaklı Hava Kirliliğinin Önlenmesi: Kural 13 ve Kural 14 kapsamında belirlenen Nitrojen oksit (NOx) ve Sülfür oksit (SOx) (partiküller (PM) dahil) Emisyon Kontrol Alanları (ECA) IMO tarafından (IMO, 2019c) ilan edilmiştir. Tablo 4'te; MARPOL EK VI Kural 13.5.1 kapsamında gemilerin inşa tarihi ve makine devir sayısına göre baca (egzost) gazlarından çıkabilecek NOx emisyon limitleri (IMO, 2019ç) gösterilmektedir. IMO tarafından ilan edilen NOx Emisyon Kontrol Alanları (NOx ECA) içerisinde sefer yapacak bir gemi için Aşama III limitleri geçerli olmaktadır. 
Tablo 4: Gemilerin İnşa Tarihi ve Makine Devir Sayısına Göre NOx Emisyon Limitleri

\begin{tabular}{|c|c|c|c|c|}
\hline \multirow[t]{2}{*}{ Aşama } & \multirow[t]{2}{*}{ İnşa tarihi } & \multicolumn{3}{|c|}{$\begin{array}{c}\text { NOx emisyon limiti (gr/kWh) } \\
\text { n = makinenin devir sayısı (d/dk) }\end{array}$} \\
\hline & & $n<130$ & $n=130-1999$ & $n \geq 2000$ \\
\hline I & 1 Ocak 2000 & 17.0 & $\begin{array}{c}45 \cdot n(-0.2) \\
\text { Örn; } 720 \mathrm{~d} / \mathrm{dk} \text { için } 12.1\end{array}$ & 9.8 \\
\hline II & 1 Ocak 2011 & 14.4 & $\begin{array}{c}44 \cdot n(-0.23) \\
\text { Örn; } 720 \mathrm{~d} / \mathrm{dk} \text { için } 9.7\end{array}$ & 7.7 \\
\hline III & 1 Ocak 2016 & 3.4 & $\begin{array}{c}9 \cdot n(-0.2) \\
\text { Örn; } 720 \mathrm{~d} / \mathrm{dk} \text { için } 2.4\end{array}$ & 2.0 \\
\hline
\end{tabular}

Kaynak: IMO, 2019ç.

Tablo 5'te ise; IMO tarafindan ilan edilen SOx Emisyon Kontrol Alanları (SOx ECA) dışında ve içinde gemilerde kullanılan yakıtların Sülfür (S) içeriği limitleri (IMO, 2019d) gösterilmektedir.

Tablo 5: SOx ECA Dışında ve İçinde Gemi Yakıtları İçin Sülfür İçeriği Limitleri

\section{SOx ECA dişında}

$4.50 \% \mathrm{~m} / \mathrm{m}$ (1 Ocak 2012'ye kadar)

$3.50 \% \mathrm{~m} / \mathrm{m}$ (1 Ocak 2012 ve sonrasında)

$0.50 \% \mathrm{~m} / \mathrm{m}$ (1 Ocak 2020* ve sonrasında)

Kaynak: IMO, 2019d.

\section{SOx ECA içinde}

1.50\% m/m (1 Temmuz 2010'a kadar)

$1.00 \% \mathrm{~m} / \mathrm{m}$ (1 Temmuz 2010 ve sonrasında)

$0.10 \% \mathrm{~m} / \mathrm{m}$ (1 Ocak 2015 ve sonrasında)

MARPOL EK VI Kural 14.1 çerçevesinde, 1 Ocak 2020'den itibaren gemilerde kullanılan herhangi bir fuel oilin içerdiği Kükürt (S) oranı \%0,50m/m'den daha fazla olamayacak ve IMO tarafından ilan edilen SOx ECA içerisine sefer yapılması durumunda ise bu oran $\% 0,10 \mathrm{~m} / \mathrm{m}$ 'den daha fazla olamayacaktır.

\section{Dünyada ve Türkiye'de Yeşil Liman/Eko Liman Uygulamaları}

IMO, 1970'li yıllardan beri gemilerden kaynalanan kirliliği önlemeye yönelik çalışmalar yürütmüş ve bunları MARPOL Sözleşmesi ile kurallara bağlamıştır. Son olarak 2005 yılında kabul edilen Ek VI ile gemi kaynaklı zararlı emisyonların minimize edilmesine yönelik kurallar yürürlüğe girmiştir. Bütün bu kurallar, istisnalar olsa da, esasen 190'dan fazla IMO üyesi ülke tarafından uygulanmaktadır. Ancak, çevre konularında inisiyatif oluşturma ve uluslararası kamuoyunun gündemine getirmede Avrupa'nın öncül rolünü özellikle vurgulamak gerekir. Tablo 6'da; AB'nin limanlarda çevresel sürdürülebilirlik ve yeşil liman konusuyla ilişkili olabilecek başlıca düzenlemeleri yer almaktadır. Görüldüğü gibi, 90’lı yıllardan itibaren, gemi kaynaklı atıkların bertarafından gemi yakıtlarının sülfur içeriğine, çevre yönetim planlarından gürültü kirliliğine, su politikasından enerji verimliliği ve yenilenebilir enerji kullanımına kadar pek çok konuda $A B$ düzenlemeleri mevcuttur ve günün koşullarına göre geliştirilmeye de devam edilmektedir. 
Tablo 6: Çevresel Sürdürülebilirlik ve Yeşil Liman Konusuyla İliş̧ili AB Düzenlemeleri

\begin{tabular}{|c|c|c|}
\hline Sayısı & Tarihi & Konusu \\
\hline $\begin{array}{l}\text { COM(2011) } \\
109 \text { final }\end{array}$ & 8 Mart 2011 & Energy Efficiency Plan 2011 \\
\hline 2009/28/EC & 23 Nisan 2009 & $\begin{array}{l}\text { Promotion of the use of energy from renewable sources and } \\
\text { amending and subsequently repealing Directives } 2001 / 77 / E C \text { and } \\
2003 / 30 / E C\end{array}$ \\
\hline 2006/32/EC & 5 Nisan 2006 & $\begin{array}{l}\text { Energy end-use efficiency and energy services and repealing Council } \\
\text { Directive } 93 / 76 / \text { EEC }\end{array}$ \\
\hline 2005/33/EC & 6 Temmuz 2005 & Amending Directive 1999/32/EC \\
\hline 2004/8/EC & 11 Şubat 2004 & $\begin{array}{l}\text { Promotion of cogeneration based on a useful heat demand in the } \\
\text { internal energy market and amending Directive } 92 / 42 / E E C\end{array}$ \\
\hline 2003/55/EC & 26 Haziran 2003 & $\begin{array}{l}\text { Common rules for the internal market in natural gas and repealing } \\
\text { Directive } 98 / 30 / E C\end{array}$ \\
\hline 2002/49/EC & 25 Haziran 2002 & Assessment and management of environmental noise \\
\hline 2001/42/EC & 21 Haziran 2001 & $\begin{array}{l}\text { Assessment of the effects of certain plans and programmes on the } \\
\text { environment }\end{array}$ \\
\hline 2000/59/EC & 27 Kasım 2000 & $\begin{array}{l}\text { Port reception facilities for ship-generated waste and cargo } \\
\text { residues }\end{array}$ \\
\hline 2000/60/EC & 23 Ekim 2000 & $\begin{array}{l}\text { Establishing a framework for Community action in the field of water } \\
\text { policy }\end{array}$ \\
\hline 1999/32/EC & 26 Nisan 1999 & $\begin{array}{l}\text { Reduction in the sulphur content of certain liquid fuels and } \\
\text { amending Directive } 93 / 12 / E E C\end{array}$ \\
\hline
\end{tabular}

Kaynak: Vaio ve Varriale, 2018:5.

Tabii ki uluslararası düzenlemeler bunlarla da sınırlı değildir. Birleşmiş Milletler Deniz Hukuku Sözleşmesi (UNCLOS: The United Nations Convention on the Law of the Sea, 1982), Denizde Can Emniyeti Uluslararası Sözleşmesi (SOLAS: International Convention for the Safety of Life at Sea, 1974), Gemilerden Kaynaklanan Kirliliğin Önlenmesine Illişkin Uluslararası Sözleşme (MARPOL 73/78), Kyoto Protokolü (1997), Montreal Protokolü, Atıkların ve Diğer Maddelerin Denize Bırakılması ile Deniz Kirliliğinin Önlenmesi Sözleşmesi (London Convention: Convention on the Prevention of Marine Pollution by Dumping of Wastes and Other Matter), Helsinki Konvansiyonu, Gemilerin Balast Suyu ve Sedimentlerinin Kontrol ve Yönetimi Uluslararası Sözleșmesi (International Convention for the Control and Management of Ships' Ballast Water and Sediments), IMO'nun Küresel Ballast Su Yönetimi Programı (IMO's GloBallast Water Management Programme), Petrol ile Deniz Kirliliğinin Önlenmesi Uluslararası Sözleşmesi OILPOL: International Convention for the Prevention of Pollution of the Sea by Oil, 1954), Petrol Kirliliğine Karşı Hazırlıkı Olma, Müdahale ve Işşbirliği Uluslararası Sözleșmesi (OPRC: International Convention on Oil Pollution Preparedness, Response and Cooperation), Petrol Kirliliği Zararının Hukuki Sorumluluğu Uluslararası Sözleşmesi (CLC: International Convention on Civil Liability for Oil Pollution Damage), Bunker Petrol Kirliliği Zararının Hukuki Sorumluluğu Uluslararası Sözleşmesi (Bunker Convention: International Convention on Civil Liability for Bunker Oil Pollution Damage, 2001), Deniz ile Tehlikeli ve Zararlı Maddelerin Taşınması ile İlgili Sorumluluk ve Zararların Karşılanması Hakkında Uluslararası Sözleşmesi (HNS: International Convention on Liability and Compensation for Damage in Connection with the Carriage of Hazardous and Noxious Substances by Sea, 1996), Birleşmiş Milletler Çevre Programı (UNEP) altında Basel Sözleşmesi (Basel Convention - under the United Nations Environment Programme), Roterdam Konvansiyonu (The Rotterdam Convention), Sahil Koruma Yasası (Coast Protection Act, 1949), Limanlar Yasası (Harbours Act, 1964), Deniz Atıkları ve Diğer Maddeler Yoluyla Deniz Kirliliğinin Önlenmesi Sözleşmesi (London Act, 1972), MARPOL 73/78, 
Liman Alanlarında Tehlikeli Maddeler Yönetmeliği (Dangerous Substances in Harbour Areas Regulations (DSHA), 1987), Çevre Koruma Yasası (Environmental Protection Act-EPA, 1990), Biyolojik Çeşitlilik Konvansiyonu (Convention on Biologic Diversity, 1992), Ulaştırma ve Bayındırlık Yasası (Transport and Works Act, 1992), Çevre Yönetim Sistemi Standardı (ISO 14001), Avrupa Ekolojik Yönetim ve Denetim Programı (EU Eco-Management and Audit Scheme-EMAS), 2001), BM Kara Kökenli Faaliyetlerden Deniz Çevresinin Korunması için Küresel Eylem Programı (UN Global Program of Action for the Protection of the Marine Environment from Land-Based Activities) gibi çevre konuları ve liman faaliyetleriyle doğrudan veya dolaylı olarak ilişkili sayılabilecek çok fazla sayıda uluslararası düzenleme bulunmaktadır.

Her ne kadar farklı başlıklar altında çeşitli düzenlemeler mevcut olsa da, IMO ve $A B$ mevzuatında "yeşil liman" kriterlerine yönelik spesifik bir düzenlemeye rastlanmamış olmakla birlikte, bu konuda Avrupa Deniz Limanları Organizasyonu (The European Sea Ports Organisation-ESPO)'nun çeşitli çalışmaları ve uygulamaları mevcuttur (Türklim, 2013). ESPO'nun Green Guide (Yeşil Rehber)" raporu incelendiğinde; Avrupa'daki yeşil liman uygulamasının "gönüllülük esası" ile yürütüldüğü, hava kalitesi yönetimi, enerji tasarrufu ve iklim değişikliği, gürültü yönetimi, atık yönetimi, su (tüketim ve kalite) yönetimi ile liman geliştirme projeleri (deniz dibi taraması ve çevresel etkileri dahil) gibi operasyonel faaliyetlerle ilgili konularda, Avrupa limanlarında ortak bir yaklaşım benimsendiği ve bu konularla ilgili zorlukların ve çözüm önerilerinin ortaya konulduğu görülmektedir (ESPO, 2012: 20-33).

Ulusal mevzuat açısından bakıldığında ise, Katı Atıkların Kontrolü Yönetmeliği, Ambalaj Atıklarının Kontrolü Yönetmeliği, Atık Pil ve Akümülatörlerin Kontrolü Yönetmeliği, Tehlikeli Atıkların Kontrolü Yönetmeliği, Hava Kalitesinin Korunması Yönetmeliği, Gemilerden Atık Alınması ve Atıkların Kontrolü Yönetmeliği, Su Kirliliği Kontrolü Yönetmeliği, Atık Yağların Kontrolü Yönetmeliği, Bitkisel Atık Yağların Kontrolü Yönetmeliği, Su Kirliliği Kontrolü Yönetmeliği, Ömrünü Tamamlamış Lastiklerin Kontrolü Yönetmeliği, Hafriyat Toprağı, İnşaat ve Yıkıntı Atıklarının Kontrolü Yönetmeliği, Toprak Kirliliğinin Kontrolü ve Noktasal Kaynaklı Kirlenmiş Sahalara Dair Yönetmelik, Çevre Kanununca Alınması Gereken İzin ve Lisanslar Hakkında Yönetmelik, Acil Durumlarda Müdahale ve Zararların Tazmini Esaslarına Dair Kanun, Denizyoluyla Taşınan Tehlikeli Yüklere Illişkin Uluslararası Kod Kapsamında Eğitim ve Yetkilendirme Yönetmeliği, İşçi Sağlığı ve İş Güvenliği Tüzüğü, Sağlık ve Güvenlik İşaretleri Yönetmeliği, Tıbbi Atıkların Kontrolü Yönetmeliği, Atık Yönetimi Genel Esaslarına İlişkin Yönetmelik, Dökme Yük Gemilerinin Güvenli Bir Şekilde Yüklenmesi ve Boşaltılması Hakkında Yönetmelik gibi çevre konuları ve liman faaliyetleriyle doğrudan veya dolaylı olarak çok fazla sayıda ulusal mevzuat bulunduğu da görülmektedir.

Türkiye'deki mevcut yeşil liman/eko liman sertifikalandırma uygulaması kapsamında, liman tesislerinin söz konusu sertifikayı alabilmeleri için adı geçen ulusal mevzuatın yanısıra ISO 9001, ISO 14001 ve OHSAS 18001 sistemlerini kapsayan entegre yönetim sistemini tesis etmiş olması, çeşitli yönetim planlarına sahip olması ve ayrıca liman operasyonunlarının türüne (konteyner, dökme yük, sıvı yük, genel kargo, kruvaziyer vb.) göre spesifik özel gerekleri karşılaması gerekmektedir. Ülkemizde de “gönüllülük esası" çerçevesinde yürütülmekte olan yeşil liman/eko liman uygulamasının kapsamı ve içeriği Deniz Ticareti Genel Müdürlüğü (DTGM) tarafından belirlenmekte olup sertifikalandırması ise yapılan protokol çerçevesinde Türk Standartları Enstitüsü 
(TSE) tarafından yapılmaktadır. Uygulama kapsamında şartları yerine getiren liman tesislerine "Yeşil Liman" sertifikası ile özel tasarlanan logonun kullanım izni verilmekte ve bir "saygınlık unsuru" olarak kamuoyuna duyurulması sağlanmaktadır (DTGM, 2019; TSE, 2019).

\section{Tartışma ve Sonuç}

Tablo 2'de, deniz taşımacılığı faaliyetleri ile bunlardan kaynaklanan çevresel etkilere ilişkin bilgiler sunulmuştur. Görüldüğü gibi, hem liman tesislerinin (alt yükleniciler de dahil) kendi faaliyetlerinden kaynaklanan hem de sık sık uğrayan gemilerin operasyonel faaliyetlerinden kaynaklanan pek çok kirlilik potansiyeli mevcuttur. Önlem alınmaması ve/veya kurallara uyulmaması halinde, söz konusu faaliyetler sırasında hava, su, toprak ve ekosisteme yönelik çevre kirliliği riskleri de ortaya çıkabilmektedir.

Çevre kirliliği, aynı zamanda ekonomik kayıp ve insan sağlığının bozulması anlamına gelmektedir. Öyle ki; gemi ve liman operasyonları kaynaklı hava kirliliğinin dünyada yılda 19.000 kişinin akciğer kanserine sebep olduğu ve 60.000 kişinin gemi ve liman kaynaklı emisyonlar nedeniyle çeşitli hastalıklara yakalanarak hayatlarını kaybettiği yetkililerce ifade edilmektedir (UBAK, 2019). Literatürde, gemi ve liman operasyonları kaynaklı hava kirliliğinin çok ciddi ekonomik maliyetleri olduğunu gösteren çalışmalara rastlamak da mümkündür. Örneğin; limanlarda oluşan deniz taşımacılığı kaynaklı emisyonların, OECD ülkelerinde bulunan en büyük ilk 50 limana yıllık maliyetinin 12 milyar Euro olduğu ve ayrıca 230 milyon kişiyi doğrudan etkilediği ifade edilmektedir (Merk, 2014:4,23).

Dolayısıyla, liman tesisleri için "sürdürülebilir çevre yönetimi" konusu, çevrenin korunması yanında çok ciddi ekonomik ve sosyal boyutları da olan, genelde ülkelerin ekonomisini ve sosyal refahını ilgilendirdiği gibi özelde limanların ticari rekabet gücünü de etkileyebilen önemli bir konudur. Başka bir deyişle, çevrenin korunması, tasarruf ve yaşam kalitesine de önemli katkılar sağlamaktadır.

Dünya deniz ticaretindeki yönelimler, denizcilik sektörünün gündeminde olan çevresel konularla da ilişkilidir. Dünya genelinde fosil yakıt kullanımının 15-20 sene içerisinde sonlandırılması ve yenilenebilir enerji kaynaklarına geçilmesi yönünde uluslararası toplumda çok ciddi bir yönelim bulunmaktadır. Bu konular, IMO'nun Deniz Çevresini Koruma Komitesi (MEPC)'nde ciddi biçimde tartışılmaktadır. Küresel ölçekte artan çevre hassasiyeti ile birlikte gelişen uluslararası normlara tam uyum sağlamak, küresel rekabet edebilirliğin önemli bir unsuru haline gelmiş durumdadır. $A B$ ve $A B D$ başta olmak üzere gelişmiş ülkeler ve toplumlar, limanlarına gelen gemilerin uluslararası çevre düzenlemeleri ve hatta bunun da ötesinde kendi ulusal düzenlemeleri ile tam uyumlu olma şartı aramakta ve hiçbir şekilde imtiyaz tanımamaktadırlar.

Bu bakımdan, liman tesislerinin (alt yükleniciler de dahil), bir taraftan çevre kirliliği ile mücadele ederken, diğer taraftan yenilenebilir enerji kaynaklarına yönelmeleri büyük önem arz etmektedir. Liman faaliyetlerinde fosil yakıt enerjisinden beslenen ekipmanların ve araçların, zararlı emisyon üretmeyen (elektrik, güneş enerjisi, rüzgar enerjisi, hidro-elektik vb. gibi) alternatif enerji kaynaklarından beslenen ekipman ve araçlarla değiştirilmesi hedeflenmelidir. Başta gemilere sahilden elektrik enerjisi sağlanması (cold-ironing) uygulaması olmak üzere, alternatif yakıtların gemilerde 
kullanımı arttıkça bu teknolojiye uygun alt yapıyı oluşturmayan liman tesisleri zamanla devre dışı kalarak rekabet gücünü kaybetme riski ile karşı karşıya kalabilirler.

Bu çalışma kapsamında yapılan inceleme neticesinde, çevre konuları ve liman faaliyetleriyle doğrudan veya dolaylı olarak ilişkili çok fazla sayıda uluslararası ve ulusal düzenleme bulunduğu görülmektedir. Buna rağmen, IMO ve $A B$ mevzuatında "yeşil liman" kriterlerine yönelik spesifik bir düzenlemeye rastlanmamış olmakla birlikte, Avrupa Deniz Limanları Organizasyonu (The European Sea Ports OrganisationESPO)'nun çeşitli uygulamaları mevcut olup (Türklim, 2013) literatürde de genellikle bu çalışmalardan bahsedilmektedir. Bir liman tesisinin, üstelik lojistik ve tedarik zinciri içerisinde yer alan bütün paydaşlarını da koordine ederek, bu kadar fazla sayıdaki düzenlemeye uyum sağlaması gerçekten bir hayli zor ve fakat aynı zamanda çok değerli bir başarıdır.

Üstelik, ESPO'nun “Yeşil Rehber (Green Guide)” isimli dokümanı incelendiğinde, rehberin uygulamasında Avrupa'da yaygın olan "liman otoritesi (port authority)" yapısının önemli bir rolü olduğu görülmektedir. Ülkemizdeki limanlarda ise, Avrupa veya Asya'daki gibi altyapı konuları da dahil geniş düzenleyici yetkileri olan ve otonom bir şekilde karar alıp uygulayabilen liman otoritesi yapısına benzer yaygın bir yapılanma bulunmamaktadır. Buna rağmen, yeşil liman/eko liman yaklaşımının Avrupa'da olduğu gibi ülkemizde de benimsenerek uygulanıyor olması önemli bir başarı olarak değerlendirilmekte ve yeşil liman/eko liman konseptinin lojistik faaliyetleri ile deniz ve çevre emniyetine önemli katkıları bulunduğu görülmektedir.

Ancak tabii ki pek çok konuda olduğu gibi yeşil liman uygulaması kapsamında da genel olarak aşılması gereken bazı kısıtıııklar söz konusudur.

Yeşil liman uygulaması konusunda aşılması gereken başlıca kısıtlılıklar; limanlarda mevzuatın uygulanmasından sorumlu kurumlar ve diğer paydaşlar arasında yetersiz iletişim ve koordinasyon, anlaşılması güç mevzuatlar, yüksek maliyet gerektiren çevre hukuku uygulamaları ve çevrenin korunmasına yönelik yetersiz ekonomik teşvik ve onaylar şeklinde ifade edilmektedir (Türklim, 2013).

\section{5. Öneriler}

Daha önce de belirtildiği gibi, ülkemizdeki yeşil liman/eko liman uygulamasının kapsamı ve içeriği DTGM tarafından belirlenmekte olup sertifikalandırması ise TSE tarafından, "gönüllük esası" çerçevesinde ve "saygınlık unsuru" olarak değerlendirilerek yapılmaktadır.

Gönüllülük esasına dayalı yürütülen söz konusu uygulama, bu yönü ile Avrupa'daki benzer uygulamalarla da örtüşmektedir.

Literatürdeki çalışmalar ve ESPO'nun “Yeşil Rehber (Gren Book)" dokümanı, liman otoritesini, liman saha operasyonlarını ve taşımacılık/lojistik zincirini kapsayan bir çevresel yönetim perspektifine vurgu yapmaktadır. Fakat, bir liman tesisinin, kendisi ile beraber lojistik ve tedarik zinciri içerisinde yer alan bütün paydaşlarını da koordine ederek çok fazla sayıda uluslararası ve ulusal düzenlemeye uyum sağlamasının, ancak ve ancak çok güçlü bir envanter ve yazılım altyapısı ile mümkün olabileceği de açıktır. Avrupa'da EcoPorts, ESPO gibi kuruluşlar, Avrupa limanlarına çeşitli araçlarla destek olmaktadırlar. Benzer şekilde, ülkemizde limancılık sektörünün bağlı olduğu çatı 
kuruluşlar tarafından da, dünyadaki en iyi örnekleri baz alarak Türk limancılık sektörüne tedarik zinciri ve çevre yönetimi konularında daha fazla destek (yazılım, uzmanlık vb.) sağlanmasının faydalı olabileceği değerlendirilmektedir.

Limancılık sektörünün küresel lojistik ve tedarik zincirinin bir parçası olması nedeniyle taşıdığı küresel nitelik ve ülkemizde yabancı menşeili liman yatırımlarının mevcudiyeti ve teşviki gibi hususlar da göz önünde bulundurulduğunda, yeşil liman/eko liman sertifikasyonunun TSE'nin yanısıra TÜRKAK akreditasyonu çerçevesinde yetki alan diğer uluslararası muteber sertifikalandırma kuruluşları tarafından da yapılabilmesi halinde, dünyada ve özellikle de Avrupa'daki sürdürülebilir çevre yönetimi ve yeşil liman/eko liman uygulamaları hakkında ülkemize know-how bilgi akışı sağlanmış olacağından dolayı mevcut uygulamanın sürekli gelişmesine de katkı sağlayabileceği değerlendirilmektedir.

Ayrıca, mevcut uygulamadaki "saygınlık unsuru” yaklaşımına ilave olarak, yeşil liman sertifikasyonunun somut teşvik unsurları (ucuz elektrik, vergi indirimi vb.) ile bağlantısının "sürdürülebilir gelişme" tanımı çerçevesinde kurulması halinde, hem sertifikasyonun hem de "cold-ironing" uygulaması başta olmak üzere yenilenebilir enerji kaynağı kullanımının Türk limancılık sektöründe daha da yaygınlaşmasına katkı sağlayabileceği değerlendirilmektedir.

Liman otoritesi yapısının ülkemize uygun olup olmadığı veya bu konuda kamu ve özel sektörün yaklaşımları gibi konular, ilgi duyan araştırmacılar tarafından farklı çalışmalarda ele alınabilir ve özellikle limanların sürdürülebilir çevre yönetimine etkisi incelenebilir. ESPO'nun uyguladığı Kendi Kendine Teşhis Yöntemi (Self Diagnosis Method-SDM)'nin Türk limanlarına adapte edilmesine yönelik de bir çalışma yapılabilir. Ayrıca, Aliağa, İskenderun ve İzmit Körfezleri başta olmak üzere limancılık faaliyetlerinin yoğun olduğu kıyı kentlerinde, turistik bölgelerde, çevresel açıdan korunması gereken bölgelerde ve Türk Boğazları bölgesinde deniz taşımacılığı kaynaklı oluşan NOx, SOx, CO2, CO, VOC, PM emisyonlarının ölçümüne ve Türkiye'nin potansiyel NOx ve SOx ECA alanlarına yönelik bilimsel çalışmalar yapılmasının da faydalı olabileceği değerlendirilmektedir.

\section{KAYNAKÇA}

Ascencio, L.M., González-Ramírez, R.G., Bearzotti, L.A., Smith, N.R., Camacho-Vallejo, J.F. (2014). A Collaborative Supply Chain Management System for a Maritime Port Logistics Chain. Journal of applied research and technology, 12(3): 444-458.

Bichou, K. (2013). Port Operations, Planning and Logistics. Informa Law from Routledge, Oxon, USA. https://content.taylorfrancis.com/books/download?dac=C2011-0-18304-

9\&isbn=9781317912712\&format=googlePreviewPdf, Erişim Tarihi: 15.10.2019.

Chengpeng, W., Di, Z. Xingping, Y, Zaili, Y. (2018). A novel model for the quantitative evaluation of green port development - A case study of major ports in China. Transportation Research Part D: Transport and Environment, 61(B): 431-443.

Council of Supply Chain Management Professionals (CSCMP). (2013). CSCMP Supply Chain Management Definitions and Glossary (Updated: August 2013). https://cscmp.org/CSCMP/Educate/SCM_Definitions_and_Glossary_of_Terms/CSCMP/Ed ucate/SCM_Definitions_and_Glossary_of_Terms.aspx?hkey=60879588-f65f-4ab5-8c4b6878815ef921, Erişim Tarihi: 15.10.2019.

Deniz Ticareti Genel Müdürlüğü (DTGM).(2019). Yeşil Liman. http://www.ubak.gov.tr/BLSM_WIYS/DTGM/tr/HTML/20120817_094504_64032_1_6434 6.html, Erişim Tarihi: 18.10.2019. 
EcoPorts. (2019). The Story of EcoPorts Building a Worldwide Network for Sharing Experience in Port Environmental Management. http://www.ecoports.com/assets/files/common/brochures/The_Story_of_EcoPorts-v8with_pictures.pdf, Erişim Tarihi: 15.10.2019.

Elbirlik, G. (2008). Türk Lojistik Sektöründe Denizyolu Taşımacılığının Önemi ve Sorunları. Yüksek Lisans Tezi. Dokuz Eylül Üniversitesi Sosyal Bilimler Enstitüsü, İzmir.

International Maritime Organisation (IMO). (2019a). UN body adopts climate change strategy for shipping. http://www.imo.org/en/MediaCentre/PressBriefings/Pages/O6GHGinitialstrategy.aspx, Erişim Tarihi: 15.10.2019.

IMO. (2019b). International Convention for the Prevention of Pollution from Ships (MARPOL). http://www.imo.org/en/About/Conventions/ListOfConventions/Pages/InternationalConvention-for-the-Prevention-of-Pollution-from-Ships-(MARPOL).aspx, Erişim Tarihi: 15.10.2019.

IMO. (2019c). Emission Control Areas (ECAs) designated under MARPOL Annex VI. http://www.imo.org/en/OurWork/Environment/PollutionPrevention/AirPollution/Pages/E mission-Control-Areas-(ECAs)-designated-under-regulation-13-of-MARPOL-Annex-VI(NOx-emission-control).aspx, Erişim Tarihi: 15.10.2019.

IMO. (2019ç). Nitrogen Oxides (NOx) - $\quad$ Regulation 13. http://www.imo.org/en/OurWork/Environment/PollutionPrevention/AirPollution/Pages/Ni trogen-oxides-(NOx)-\%E2\%80\%93-Regulation-13.aspx, Erişim Tarihi: 15.10.2019.

IMO. (2019d). Sulphur oxides (SOx) and Particulate Matter (PM) - Regulation 14. http://www.imo.org/en/OurWork/Environment/PollutionPrevention/AirPollution/Pages/Su Iphur-oxides-(SOx)-\%E2\%80\%93-Regulation-14.aspx, Erişim Tarihi: 15.10.2019.

Jastrząbek, A.O., Pawłowska, B., Czermański, E. (2018). Polish sea ports and the Green Port concept. SHS Web of Conferences 57, 01023 (2018), 1-11.

Mataracı, G.D.G. (2016). Yeşil Liman Yaklaşımı ve Liman İşletmelerinde Sürdürülebilirlik. Yüksek Lisans Tezi. İstanbul Teknik Üniversitesi Fen Bilimleri Enstitüsü, İstanbul.

Meark, O. (2014). Shipping Emissions in Ports. OECD International Transport Forum (ITF) Discussion Paper 2014-20, Paris. https://www.itf-oecd.org/sites/default/files/docs/dp201420.pdf, Erişim Tarihi: 15.10.2019.

The European Sea Ports Organisation (ESPO). (2012). ESPO Green Guide. https://www.espo.be/media/espopublications/espo_green\%20guide_october\%202012_fi nal.pdf, Erişim Tarihi: 15.10.2019.

Türkiye Liman İşletmecileri Derneği (Türklim). (2013). Yeşil Liman Raporu/Yeşil Liman Politika, Düzenleme ve Uygulamaları. Türkiye Limancılık Sektörü Raporu. http://www.turklim.org/kport/yesil_liman/upload/Yesil-Liman-Turklim-Raporu.pdf, Erişim Tarihi: 15.10.2019.

Türk Standartları Enstitüsü (TSE). (2019). Yeşil Liman/Eko Liman. https://www.tse.org.tr/IcerikDetay?ID=2049, Erişim Tarihi: 18.10.2019.

UBAK. (2019). "Yeşil Liman / Eko liman projesi" ile ülkemizin ilk "Yeşil Liman" ünvanlı limanı belirlendi."

http://www.ubak.gov.tr/BLSM_WIYS/DTGM/tr/Belgelik/guncel_haber/20150730_140002 _64032_1_64480.html, Erişim Tarihi: 18.10.2019.

Vaio, V. \& Varriale, I. (2017). Management Innovation for Environmental Sustainability in Seaports: Managerial Accounting Instruments and Training for Competitive Green Ports beyond the Regulations. Sustainability 2018, 10(783): 1-35.

Zhen, L., Zhue, D., Murong, L., Yan, R., Wang, S. (2019). Operation management of green ports and shipping networks: overview and research opportunities. Frontiers of Engineering Management, 6(2):152-162. 